\title{
Onychomadesis after hand-foot-and-mouth disease
}

\author{
Xue-ling Gan MBBS, Tang-de Zhang MD
}

Cite as: CMAJ 2017 February 21;189:E279. doi: 10.1503/cmaj.160388

A

seven-year-old boy presented with a fourweek history of nail shedding. The patient developed nail changes three weeks after recovering from hand-foot-and-mouth disease diagnosed by rectal swab, which was positive for human enterovirus 71 . Initially, a grey-white patch appeared on the bottom of his nails and spread. Then, beginning with the lunulae, his nails shed over the course of two weeks from the bottom to the free border of the nail. Meanwhile, fresh, thin pink nails grew slowly. Physical examination showed that multiple fingernails and toenails had shed completely or partially (Figure 1). Beau lines, horizontal grooves running across the nail plates, were noted. Some nails showed a cloudlike, grey-white colour. No periungual rashes or swelling were found. We diagnosed onychomadesis following hand-foot-and-mouth disease.

Hand-foot-and-mouth disease typically manifests as fever and vesicles involving the hands, feet and mouth, mainly affecting children older than five years. ${ }^{1}$
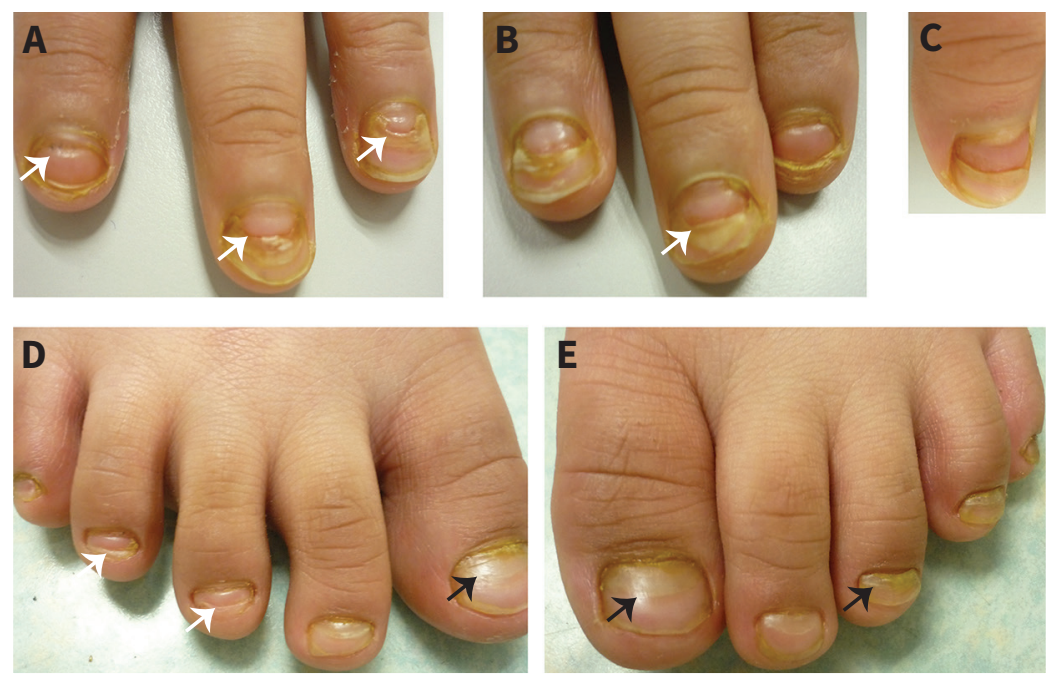

Figure 1: Partial or complete nail shedding in a seven-year-old boy who had hand-footand-mouth disease eight weeks earlier. Panels A-C show new nail growth, panels A, B and $D$ show Beau lines (white arrows), and panels $D$ and $E$ show grey-white colour changes (black arrows).

\section{Enterovirus 71 and coxsackievirus A16 are the most} common causative agents among a dozen enteroviruses associated with the condition. ${ }^{1,2}$ Onychomadesis is a late complication that occurs four to six weeks after the illness onset. ${ }^{2,3}$ It is usually selflimited and requires no treatment. ${ }^{4}$ Nail abnormalities range from leukonychia and Beau lines to partial or complete nail shedding. ${ }^{5}$ The pathogenesis of onychomadesis associated with hand-foot-andmouth disease is incompletely understood. It may involve brief inhibition of nail-matrix proliferation caused by periungual inflammatory reactions or enteroviruses affecting the nail matrix more directly. ${ }^{5}$

\section{References}

1. Huang X, Wei H, Wu S, et al. Epidemiological and etiological characteristics of hand, foot, and mouth disease in Henan, China, 2008-2013. Sci Rep 2015;5:8904.

2. Yan X, Zhang ZZ, Yang ZH, et al. Clinical and etiological characteristics of atypical hand-foot-and-mouth disease in children from Chongqing, China: a retrospective study. BioMed Res Int 2015 Nov. 26 [Epub ahead of print]. doi: 10.1155/2015/802046.

3. Guimbao J, Rodrigo P, Alberto MJ, et al. Onychomadesis outbreak linked to hand, foot, and mouth disease, Spain, July 2008. Euro Surveill 2010;15:19663.

4. Mathes EF, Oza V, Frieden IJ, et al. "Eczema coxsackium" and unusual cutaneous findings in an enterovirus outbreak. Pediatrics 2013;132:e149-57.

5. Hardin J, Haber RM. Onychomadesis: literature review. Br J Dermatol 2015; 172:592-6.
Competing interests: None declared.

This article has been peer reviewed.

The authors have obtained patient consent.

Affiliation: Department of Dermatology, Zhujiang Hospital, Southern Medical University, Guangzhou, China

Correspondence to: Tang-de Zhang, tdgz@medmail.com.cn

Clinical images are chosen because they are particularly intriguing, classic or dramatic. Submissions of clear, appropriately labelled high-resolution images must be accompanied by a figure caption. A brief explanation (300 words maximum) of the educational significance of the images with minimal references is required. The patient's written consent for publication must be obtained before submission. 